\title{
Polyurethane-degrading fungi from soils contaminated with rocket propellant and their ability to decompose alkyne terminated polybutadiene with urethane
}

\author{
Ren $\mathrm{GC}^{1,2,4 \dagger}$, Pang $\mathrm{AM}^{5 \dagger}$, Gao $\mathbf{Y}^{1,4}$, Wu $\mathrm{SX}^{5}$, Ge $\mathrm{ZQ}^{5}$, Zhang $\mathrm{TF}^{5}$, \\ Wanasinghe $\mathrm{DN}^{3}$, Khan $\mathrm{S}^{3}$, Mortimer $\mathrm{PE}^{3}, \mathrm{Xu} \mathrm{JC}^{3}$ and $\mathrm{Gui}^{3 *}$
}

${ }^{1}$ Center of Excellence in Fungal Research, Mae Fah Luang University, Chiang Rai 57100, Thailand

${ }^{2}$ Guiyang Nursing Vocational College, Guiyang 550081, Guizhou, China

${ }^{3}$ Honghe Center for Mountain Futures, Kunming Institute of Botany, Chinese Academy of Sciences, Honghe County 654400, Yunnan, China

${ }^{4}$ School of Science, Mae Fah Luang University, Chiang Rai 57100, Thailand

${ }^{5}$ Science and Technology on Aerospace Chemical Power Laboratory, Hubei Institute of Aerospace Chemotechnology, Xiangyang, 441003, Hubei, China

*These authors contributed equally to this paper

Ren GC, Pang AM, Gao Y, Wu SX, Ge ZQ, Zhang TF, Wanasinghe DN, Khan S, Mortimer PE, Xu JC, Gui H 2021 - Polyurethane-degrading fungi from soils contaminated with rocket propellant and their ability to decompose alkyne terminated polybutadiene with urethane. Studies in Fungi 6(1), 224-239, Doi 10.5943/sif/6/1/15

\begin{abstract}
A large amount of propellant materials are produced every year, and storage and disposal of these propellant materials seriously contributes to environmental pollution. Alkyne terminated polybutadiene with urethane segments (PUPB) is the macromolecule backbone of these propellant materials, and degradation of PUPB is central to the eco-friendly treatment of propellant materials. In this study, we isolated a polyurethane (PU)- and PUPB-degrading fungus from soils contaminated with rocket propellant, and the fungus H14 was identified as Fusarium solani (Mart.) Sacc. based on macro- and micro-morphology as well as phylogenetic analyses. The ability of $F$. solani H14 to degrade PU film and PUPB patches was evaluated via mass loss, scanning electron microscopy (SEM) and enzyme production ability. Mass loss analyses revealed a $25.8 \%$ reduction in mass of PU and $1.3 \%$ reduction in mass of PUPB after $F$. solani $\mathrm{H} 14$ was incubated with PU and PUPB for 90 days, respectively. We found that $F$. solani $\mathrm{H} 14$ mycelia significantly colonized both PU and PUPB. SEM images showed that the surface of PU films and PUPB patches formed holes, underwent folding and experienced damage as well as irregular fissuring from the erosion of fungal hypha. Moreover, two possible degradative enzymes, lipase and esterase, were produced by $F$. solani. Our study opens a new avenue of research for eco-friendly treatments of explosive materials and propellants. This paper represents the first article on the degradation of PUPB patches.
\end{abstract}

Keywords - enzyme - Fusarium solani - mass loss - PU - PUPB

\section{Introduction}

Polyurethane (PU) is a synthetic polymer produced by reacting polyols and polyisocyanates that is widely utilized in medical, agricultural, automotive and industrial fields (Howard 2002, 
Tokiwa \& Calabia 2009, Krasowska et al. 2012, Magnin et al. 2019, Tan \& Ohwada 2019). In particular, polyurethane-based binder systems are extensively used in composite solid propellants, usually consisting of PU and its derivatives like alkyne terminated polybutadiene with urethane segments (PUPB), ammonium perchlorate (AP), aluminum powder (Al) solids, binders and other additives like plasticizers (Bunyan et al. 1993, Haska et al. 1997, Libardi et al. 2010). Solid propellants are widely used in space and tactical systems as energetic materials (Davenas 2003, Libardi et al. 2010). An increasing amount of solid propellants are produced every year, all of which need disposal owing to their deterioration or obsolescence. In the past, solid propellant materials have been disposed via ocean dumping, open area burning or detonation in a safe zone (Gautam et al. 2007, Mahajan \& Gupta 2015); however, when solid propellants are released into the biosphere, energetics are xenobiotic contaminants that threaten ecosystems, humans and other biota with toxic waste materials (Pichtel 2012). These conventional means of processing propellants or other polymer materials can worsen land and water pollution while exacerbating safety concerns. Therefore, in order to address environmental pollution problems caused by propellant waste processing, sustainable solutions are urgently needed for biodegrading the PU and PUPB that comprise the backbone structures of propellant materials. Out of all currently available methods, microbial degradation has been accepted as the most environmentally friendly method for the disposal of these polymer materials (Sangale et al. 2019, Sarkhel et al. 2019).

Among all the major matrices of solid propellants, no microorganism capable of directly degrading the PUPB matrix has been reported. However, recent advances in our understanding of how other types of PU biodegrade suggest how to biologically process and degrade PUPB in the future (Mathur \& Prasad 2012, Khan et al. 2017). Some studies have assessed the potential and characteristics of fungi associated with PU degradation, while other studies have evaluated the extracellular enzymes used by fungi to utilize PU as a carbon source (Álvarez-Barragán et al. 2016, El-Morsy et al. 2017, Pathak \& Navneet 2017, Khan et al. 2020). For example, El-Morsy et al. (2017) isolated Monascus sp., which can degrade PU from plastic-contaminated soils in Egypt. Khan et al. (2020) also reported that Aspergillus flavus isolated from the intestines of crickets can degrade PU with a mean mass loss of $1.9 \%$ per week.

In this study, we aimed to screen different fungal strains from explosive materialscontaminated soils and test their ability to degrade standard PU film and PUPB patches. Initial identification analysis was also conducted to identify fungal strains with the potential to degrade PU and PUPB. Here, we report Fusarium solani capable of degrading standard PU films with the potential ability to degrade PUPB patches in laboratory conditions as well as its taxonomic identification and enzyme activity.

\section{Materials \& methods}

\section{Sample collection}

Soil samples contaminated by explosive materials were collected from central China. Soil collection was carried out using a sterilized auger. From each site, five soil sub samples were collected while maintaining $5 \mathrm{~cm}$ soil depth from the surface layer. Collected soil samples were placed in sterilized bags and thoroughly mixed. Samples were transported to the laboratory and stored at $4^{\circ} \mathrm{C}$ for further analyses.

\section{Preparation of PU film and the PUPB patch}

The standard PU used in the present study was a type of polyester polyurethane, (Poly ]4,4' methylenebis (phenyl isocyanate) -alt-1, 4-butanediol/di (propylene glycol)/polycaprolactone[ (PU/PCL), Sigma-Aldrich Corporation, CAS: 68084-39-9, USA). PU beads (22 g) were dissolved in $600 \mathrm{ml}$ of tetrahydrofuran (Aladdin Industrial Corporation, China) and oscillated in a reciprocating multi-amplitude orbital shaker for 1 day at $30^{\circ} \mathrm{C}$ (ZWF-200, Zhicheng, China). The PU solution was then poured onto petri dishes $(10 \mathrm{~mL} /$ per dish) and allowed to solidify for $48 \mathrm{~h}$ in a desiccator at room temperature. Dried PU films were removed from the petri dishes and stored at 
room temperature. PUPB materials were prepared using 2, 4-toluene diisocyanate (TDI), propargyl (3-isocyanato-4-methylphenyl), carbamate (PTI) and HTPB, all of which were provided by the Aerospace Chemical Power Laboratory of Hubei Institute of Aerospace Chemotechnology, China. PUPB patches were made by cutting PUPB material into $1.5 \times 2.0 \mathrm{~cm}$ rectangles $0.2 \mathrm{~cm}$ thick.

\section{Isolation testing of fungi from contaminated soil}

The serial dilution plating method was used to dilute soil samples as described by Waksman (1922) with the purpose of minimizing fungi in the soil of each dilution. Soil sample dilution was conducted in two replicates, and each replicate was diluted four times and labeled $10^{-1}$ to $10^{-4}$. At each level of dilution, soil extracts were obtained by shaking $1 \mathrm{~g}$ of soil in $9 \mathrm{~mL}$ of sterilized water for 1 hour and next centrifuged for $10 \mathrm{~min}$ at $2000 \mathrm{rpm}$. Supernatants were serially diluted under aseptic operating conditions and $1 \mathrm{~mL}$ of $10^{-1}$ diluted fungal solution was placed into the centrifuge tube containing $9 \mathrm{~mL}$ sterile water, which was then shook and mixed evenly to obtain a $10^{-2}$ concentration of fungal solution. Finally, $20 \mu \mathrm{L}$ of each concentration of diluent was placed onto a Potato Dextrose Agar (PDA) petri dish with a pipette and spread evenly across the surface of the petri dish using a sterile glass coating rod.

Upside-down culture dishes were incubated under dark conditions at $28^{\circ} \mathrm{C}$ for $3-5$ days. Postincubation fungal colonies were transferred to new PDA plates. Pure fungal cultures were obtained by sub-culturing each of the different colonies onto new PDA plates. Finally, 29 strains were obtained.

\section{Degradative testing of strains}

A sterilized razor blade was used to divide the colony of each strain into $2 \mathrm{~mm}$ sections, after which one piece of each purified culture was transferred to Malt Extract Agar (MEA), and a sterilized PU film with a diameter of $80 \mathrm{~mm}$ was laid over the surface of each medium (three replicates). Simultaneously, a purified culture section from each colony was transferred to MEA, and a sterilized PUPB patch was laid over the surface of each MEA medium (three replicates). Cultures were incubated at room temperature $\left(26 \pm 2^{\circ} \mathrm{C}\right)$ for 90 days in a sterile culture room, and decomposition of PU and PUPB was observed.

\section{Selection and identification of degradative fungal strains}

\section{Selection testing of degradative strains via mass loss of degraded PU film and PUPB patch}

The abilities of 29 fungal strains to degrade PU and PUPB were tested. Fungal degradative abilities were analyzed by determining mass loss after 90 days of observation. After 90 days of incubation, PU films and PUPB patches were both collected, washed thoroughly with distilled water, shade-dried and weighed. According to collected data, mass loss of PU films and PUPB patches were calculated using the following formula (Mathur \& Prasad 2012).

$$
\mathrm{M}(\%)=\frac{(\mathrm{M} 1-\mathrm{M} 2) \times 100}{\mathrm{M} 1}
$$

In the formula, M (\%) is the percentage of mass loss, M1 $(\mathrm{g})$ is the initial mass before degradation and M2 $(\mathrm{g})$ is the final mass after degradation.

\section{Macro- and micro-morphological photography}

Fungal colonies were incubated at $25^{\circ} \mathrm{C}$ for four weeks on PDA. Micro-morphological structures were photographed using a Nikon compound microscope (Nikon ECLIPSE Ni) fitted with a Canon (EOS 600 D) digital camera. Micro-morphological changes in PU and PUPB structures after fungal degradation were observed via Scanning Electron Microscope (SEM, Sigma 300). Measurements were taken using the Tarosoft (R) Image Frame Work program. Images used for figures were processed with Adobe Photoshop CS6. 


\section{DNA extraction, PCR amplification, sequencing and phylogenetic analyses}

Genomic DNA was extracted from the mycelium grown on PDA at $25^{\circ} \mathrm{C}$ for four weeks using Biospin Fungus Genomic DNA Extraction Kit (BioFlux ${ }^{\circledR}$, Hangzhou, China). Three genes were used in our study, viz. internal transcribed spacer region (ITS) using primer pair ITS5/ITS4 (White et al. 1990), the large subunit nuclear ribosomal (LSU) using primer pair LR0R/LR5 (Vilgalys \& Hester 1990), the translation elongation factor 1-alpha gene (tef1- $\alpha$ ) using primer pair EF1/EF2 (O'Donnell et al. 1998) and the second largest subunit of RNA polymerase II (rpb2) using primer pair 5f2/11 ar (Liu et al. 1999, Reeb et al. 2004). Amplification reactions were performed in

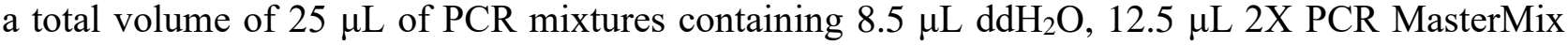
(TIANGEN Co., China), $2 \mu \mathrm{L}$ DNA template and $1 \mu \mathrm{L}$ of each primer. The PCR thermal cycling program for LSU, ITS and tef1- $\alpha$ were set as described in Wang et al. (2019) PCR products were sent for sequencing at Qingke Company, Kunming City, Yunnan Province, China. Sequences were deposited in GenBank (Table 1).

Sequences of representative taxa were retrieved from GenBank (http://www.ncbi.nlm.nih.gov/), and accession numbers are listed in Table 1. Newly generated sequences in this study were assembled using BioEdit 7.0.9.0 (Hall 1999). Individual gene regions were separately aligned in the MAFFT v.7.110 web server (http://mafft.cbrc.jp/alignment/server/) (Katoh et al. 2019). Gene alignments were improved by manually deleting ambiguous regions plus gaps and combined using BioEdit 7.2.3. Final alignments containing LSU, ITS, tef1- $\alpha$ and $\mathrm{rpb} 2$ were converted to NEXUS format (.nxs), employing CLUSTAL X (2.0) (Thompson et al. 1997). The FASTA format was translated into PHYLIP format via Alignment Transformation Environment (ALTER) online program (http://www.sing-group.org/ALTER/) and used for maximum likelihood analysis. Maximum likelihood analysis (ML) was carried out in CIPRES Science Gateway v.3.3 (http://www.phylo.org/portal2/; Miller et al. 2010) under RAxML-HPC2 on XSEDE (8.2.12) (Stamatakis 2014) with the GTR+GAMMA substitution model and 1,000 bootstrap iterations. Bayesian analyses of six simultaneous Markov chains were run for 2,000,000 generations, and trees were sampled every 100th generations. Phylogenetic trees were visualized in FigTree v1.4.0 (http://tree.bio.ed.ac.uk/software/figtree/, Rambaut 2012). The constructed tree was edited using Microsoft PowerPoint and saved as a PDF format.

\section{Enzyme activity determination}

For detecting lipase, esterase and protease activities, cultured fungal mycelia were transferred to a peptone agar medium ( $1 \%$ peptone, $0.5 \% \mathrm{NaCl}, 0.01 \% \mathrm{CaCl} 2 \cdot \mathrm{H} 2 \mathrm{O}, 1.5 \%$ agar) $(\mathrm{w} / \mathrm{v}), \mathrm{PDA}$ medium ( $1 \%$ peptone, $0.1 \%$ yeast extract, $0.005 \% \mathrm{CaCl} 2,1.5 \%$ agar $)(\mathrm{w} / \mathrm{v})$ and basal medium $(2 \%$ sucrose, $0.5 \%$ yeast extract, $2 \% \mathrm{KCl}$ and $1.5 \%$ agar) (w/v), respectively (Sierra 1956, Castro et al. 1992, Vermelho et al. 1996, El-Morsy et al. 2017). Peptone agar medium was supplemented with $1 \%$ of autoclaved tween 80, PDA medium was supplemented with $1 \%$ tween 20 (El-Morsy et al. 2017). Plates were incubated at $28^{\circ} \mathrm{C}$ for 7 days. Protease production was detected by staining the medium with 0.25\% Coomassie brilliant blue (methanol-acetic acid-water 5:1:4 (v/v/v); Beijing Solarbio Science and Technology Co., China) (Vermelho et al. 1996). An opaque halo could be easily observed around the colonies, indicating tested micro-organisms experienced lipolytic activity on the peptone agar medium (Sierra 1956). Esterase production by the fungi strain was indicated by a white precipitate of calcium salt around colonies on the PDA (Castro et al. 1992). Protease production by the fungal isolates was indicated by the formation of clear zones around colonies on the basal medium (Vermelho et al. 1996). Results were evaluated by calculating an index of relative enzyme activity (RA) (Bradner et al. 1999). RA was calculated using the following equation, and diameters were measured in $\mathrm{cm}$.

$$
\mathrm{RA}=\frac{\text { (clear zone diameter }- \text { colony diameter })}{\text { clear zone diameter }}
$$


Table 1 Taxa names, strain numbers, host information, locations and corresponding GenBank accession numbers of the sequences used for the phylogenetic analyses

\begin{tabular}{|c|c|c|c|c|c|c|c|}
\hline \multirow[t]{2}{*}{ Taxon name } & \multirow[t]{2}{*}{ Strain number } & \multirow[t]{2}{*}{ Isolate habitat/host } & \multirow[t]{2}{*}{ Location } & \multicolumn{4}{|c|}{ GenBank accession numbers } \\
\hline & & & & LSU & ITS & tef1-a & $r p b 2$ \\
\hline Geejayeesia atrofusca & NRRL 22316 & Staphylea trifolia & USA & AF178392 & AF178423 & AF178361 & JX171609 \\
\hline Fusarium catenata & NRRL 54992 & $\begin{array}{l}\text { Zebra shark multiple } \\
\text { tissues }\end{array}$ & USA & MG189913 & KC808255 & KC808213 & KC808354 \\
\hline Fusarium catenata & NRRL $54993^{\mathrm{T}}$ & $\begin{array}{l}\text { Zebra shark multiple } \\
\text { tissues }\end{array}$ & USA & MG189914 & KC808256 & КС808214 & KC808355 \\
\hline Fusarium croci & CBS 115659 & Potato & Germany & JX435206 & JX435206 & JX435156 & JX435256 \\
\hline Fusarium croci & CBS $142423^{\mathrm{T}}$ & Citrus sinensis & Italy & LT746264 & LT746264 & LT746216 & LT746329 \\
\hline Fusarium croci & СРC 27187 & Citrus sinensis & Italy & LT746265 & LT746265 & LT746217 & LT746330 \\
\hline Fusarium cyanescens & $\begin{array}{l}\text { CBS } 518.82^{\mathrm{T}}= \\
\text { NRRL } 37625\end{array}$ & Human foot & The Netherlands & EU329684 & EU329684 & FJ240353 & EU329637 \\
\hline Fusarium falciformis & $\begin{array}{l}\text { CBS } 318.73= \\
\text { NRRL } 22660\end{array}$ & Trichosanthes dioica & India & JX435208 & JX435208 & JX435158 & JX435258 \\
\hline Fusarium falciformis & CBS $475.67^{\mathrm{T}}$ & Human & Puerto Rico & MG189915 & MG189935 & LT906669 & LT960558 \\
\hline Fusarium gamsii & $\begin{array}{l}\text { CBS } 217.53= \\
\text { NRRL } 22655\end{array}$ & Plywood & Nigeria & MG189916 & MG189936 & DQ247637 & LT960559 \\
\hline Fusarium gamsii & $\begin{array}{l}\text { CBS } 143207^{\mathrm{T}}= \\
\text { NRRL } 32323\end{array}$ & $\begin{array}{l}\text { Human bronchoalveolar } \\
\text { lavage fluid }\end{array}$ & US & 52 & 4420 & 6951 & EU329576 \\
\hline Fusarium haematococa & CBS $119600^{\mathrm{ET}}$ & Dying tree & Sri Lanka & KM231664 & KM231797 & DQ247510 & LT960561 \\
\hline Fusarium illudens & NRRL 22090 & Beilschmiedia tawa & New Zealand & AF178362 & AF178393 & AF178326 & JX171601 \\
\hline $\begin{array}{l}\text { Fusarium } \\
\text { keratoplastica }\end{array}$ & NRRL 43373 & Contact lens & Malaysia & EF453072 & EF453072 & EF452920 & EF469959 \\
\hline Fusarium lichenicola & NRRL 28030 & Huma & Tha & DQ236397 & DQ094355 & DQ246877 & EF470146 \\
\hline Fusarium lichenicola & NRRL 34123 & Human eye & India & DQ236687 & DQ094645 & DQ247192 & EU329635 \\
\hline Fusarium macrospora & CBS $142424^{\mathrm{T}}$ & Citrus sinensis & Italy & LT746281 & LT746266 & LT746218 & LT746331 \\
\hline Fusarium macrospora & CPC 28192 & Citrus sinensis & Italy & LT746282 & LT746267 & LT746219 & LT746332 \\
\hline Fusarium mahasenii & CBS $119594^{\mathrm{T}}$ & Dead branch of live tree & Sri Lanka & JF433045 & JF433045 & DQ247513 & LT960563 \\
\hline Fusarium metavorans & $\begin{array}{l}\text { CBS } 130400= \\
\text { NRRL } 43489\end{array}$ & Human cornea & USA & DQ790528 & DQ790528 & DQ790484 & DQ790572 \\
\hline Fusarium metavorans & $\begin{array}{l}\text { CBS } 143194= \\
\text { NRRL } 22782\end{array}$ & Human corneal ulcer & Spain & EU329670 & EU329670 & DQ246850 & EU329528 \\
\hline Fusarium petroliphila & $\begin{array}{l}\text { NRRL } 46706= \\
\text { FMR } 8340\end{array}$ & Human blood & Qatar & EU329715 & EU329715 & NA & EU329664 \\
\hline
\end{tabular}


Table 1 Continued.

\begin{tabular}{|c|c|c|c|c|c|c|c|}
\hline \multirow[t]{2}{*}{ Taxon name } & \multirow[t]{2}{*}{ Strain number } & \multirow[t]{2}{*}{ Isolate habitat/host } & \multirow[t]{2}{*}{ Location } & \multicolumn{4}{|c|}{ GenBank accession numbers } \\
\hline & & & & $\overline{\text { LSU }}$ & ITS & tef1-a & $r p b 2$ \\
\hline Fusarium plagianthi & NRRL 22632 & Hoheria glabrata & New Zealand & AF178386 & AF178417 & AF178354 & JX171614 \\
\hline $\begin{array}{l}\text { Fusarium } \\
\text { pseudensiformis }\end{array}$ & $\begin{array}{l}\text { CBS 241.93= } \\
\text { NRRL } 53635\end{array}$ & Human & Suriname & JX435198 & JX435198 & JX435148 & JX435248 \\
\hline $\begin{array}{l}\text { Fusarium } \\
\text { pseudensiformis }\end{array}$ & CBS $125729^{\mathrm{T}}$ & Unknown dead tree & Sri Lanka & KC691584 & KC691584 & DQ247512 & NA \\
\hline Fusarium solani & $\begin{array}{l}\text { CBS } 140079^{\mathrm{ET}}= \\
\text { NRRL } 66304= \\
\text { FRC S-2364 }\end{array}$ & Solanum tuberosum & Slovenia & KT313633 & KT313633 & KT313611 & KT313623 \\
\hline Fusarium solani & $\begin{array}{l}\text { NRRL } 32484= \\
\text { FRC S-1242 }\end{array}$ & Human & USA & DQ236491 & DQ094449 & DQ246982 & EU329583 \\
\hline Fusarium solani & NRRL 43474 & Human eye & USA & EF453097 & EF453097 & EF452945 & EF469984 \\
\hline Fusarium solani & $\begin{array}{l}\text { KUMCC 20- } \\
0230\end{array}$ & Soil & China & JX435189 & MW393522 & MW460712 & MW460711 \\
\hline Fusarium suttoniana & CBS 124892 & Human nail & Gabon & DQ236659 & JX435189 & DQ247163 & JX435239 \\
\hline Fusarium suttoniana & $\begin{array}{l}\text { CBS } 143214^{\mathrm{T}}= \\
\text { NRRL } 32858\end{array}$ & Human wound & USA & MG189926 & DQ094617 & LT906672 & EU329630 \\
\hline Fusarium tonkinensis & $\begin{array}{l}\text { CBS } 115.40^{\mathrm{T}}= \\
\text { NRRL } 53586= \\
\text { IMI } 113868\end{array}$ & Musa sapientum & Vietnam & MG189927 & MG189941 & LT906673 & LT960564 \\
\hline Fusarium tonkinensis & CBS 143038 & Human cornea & The Netherlands & EF453092 & MG189942 & EF452940 & LT960565 \\
\hline Fusarium vasinfecta & $\begin{array}{l}\text { CBS 130182= } \\
\text { NRRL } 43467\end{array}$ & Human & USA & AF178392 & EF453092 & AF178361 & EF469979 \\
\hline
\end{tabular}

Our strain sequence is indicated in bold. "NA" sequences are unavailable. Ex-type strains are indicated with superscript "T". Ex-epitype strains are indicated with superscript "ET"

\section{Results}

\section{Screening and isolation of PU- and PUPB-degrading fungi}

Biodegradative capacity was monitored by measuring the mass loss of PU films and PUPB patches before and after incubation with isolated fungus (Ibrahim et al. 2011). Out of the 29 monitored fungal strains, the fungal isolate strain H14 reduced the mass of PU films and PUPB patches to a total loss of $25.8 \%$ and $1.3 \%$, respectively, after 3 months (values were arrived at by averaging of three replicates, Table 2). Results showed that fungal strain $\mathrm{H} 14$ has the greatest ability for PU degradation compared to other fungal strains. Mass loss values also showed H14 has the ability to degrade 
PUPB patches (Table 2).

Table 2 PU film and PUPB patch mass loss resulting from inoculated Fusarium solani H14

\begin{tabular}{lllllll}
\hline Polymer type & No. & M1 $(\mathbf{g})$ & M2 $(\mathrm{g})$ & Difference $(\mathrm{g})$ & M $(\%)$ & Average M (\%) \\
\hline PU & 1 & 0.4026 & 0.3020 & 0.1006 & 24.98 & \\
& 2 & 0.4002 & 0.2895 & 0.1105 & 27.66 & 25.8 \\
PUPB & 3 & 0.3985 & 0.3001 & 0.9840 & 24.69 & \\
& 1 & 0.3791 & 0.3741 & 0.0050 & 1.32 & \\
& 2 & 0.3375 & 0.3334 & 0.0041 & 1.21 & 1.3 \\
\hline
\end{tabular}

Identification of PU- and PUPB-degrading fungi

\section{Taxonomy}

Fusarium solani (Mart.) Sacc., Michelia 2(no. 7): 296 (1881).

Fig. 1

Index Fungorum number: IF190352; Facesoffungi number: FoF01873

$=$ Neocosmospora solani (Mart.) L. Lombard \& Crous, Stud. Mycol. 80: 228 (2015)

Morphology description - Colonies on PDA (Fig. 1), reaching 20-25 mm diam., after four weeks at $25^{\circ} \mathrm{C}$, mycelium white, floccose, radiate, with abundant aerial mycelium, circular, umbonate at the center, margins entire, texture velvety. Reverse luteous. Conidiophores borne on aerial mycelium, 50-100 $\mu \mathrm{m}$ long, slightly tapering upward, micronematous, mononematous, erect, simple, straight or slightly flexuous, smooth-walled, thin-walled, hyaline, sometimes reduced to conidiogenous cells. Conidiogenous cells monoblastic, integrated, determinate, terminal, hyaline. Conidia $14-25 \times 3.5-6(\overline{\mathrm{x}}=18.6 \times 5.1, \mathrm{n}=30) \mu \mathrm{m}$, solitary, acrogenous, simple, smooth-walled, 2-3-septate, straight to curved, hyaline, ellipsoidal, reniform.

Material examined - central China, from soils contaminated with explosive materials, 21 December 2019, Heng Gui, HKAS 112165, living culture KUMCC 20-0230.

\section{Phylogenetic analyses}

The phylogenetic analysis was conducted with 34 taxa in Fusarium and one outgroup taxon, Geejayeesia atrofusca (NRRL 22316). The aligned sequence matrix comprised tree gene regions including gaps (LSU: $833 \mathrm{bp}$, ITS: $498 \mathrm{bp}$, tef1- $\alpha$ : $712 \mathrm{bp}$ and rpb2: $854 \mathrm{bp}$ ) for a total of 2897 characters. The RAxML analysis of the combined dataset yielded a best scoring tree with a final ML optimization likelihood value of (-10227.648965). Estimated base frequencies were as follows: $\mathrm{A}=0.240280, \mathrm{C}=0.278119, \mathrm{G}=0.257975, \mathrm{~T}=0.223626$; substitution rates $\mathrm{AC}=2.083626, \mathrm{AG}$ $=4.760418, \mathrm{AT}=2.617861, \mathrm{CG}=1.090249, \mathrm{CT}=10.654651, \mathrm{GT}=1.00$; and gamma distribution shape parameter $\alpha=0.166032$. In Bayesian posterior analysis, GTR $+\mathrm{I}+\mathrm{G}$ model was used for LSU and ITS, GTR $+\mathrm{G}$ model was used for $t e f 1-\alpha$ and $\mathrm{SYM}+\mathrm{I}+\mathrm{G}$ model was used for $r p b 2$. In the phylogenetic tree obtained from ML and BI analysis (Fig. 2), our strain was positioned among the group of $F$. solani with high bootstrap support (100\% ML and 1.00 BYPP, Fig. 2), indicating our strain is $F$. solani.

\section{Degradation of PU films and PUPB patches by Fusarium solani H14}

After 3 months of heavy fungal colonization by Fusarium solani H14, the surface of the PU film was discolored, its color changed from white to yellowish-brown and surface aberrations, damage and yellow spots appeared after being thoroughly washed. There were conspicuous changes on the PU film surface (Fig. 3). At the same time, visible mycelium could be seen attached to the surface of the PUPB patch (Fig. 4).

\section{Scanning electron microscopy}

Scanning electron microscopy was performed on PU films and PUPB patches 90 days after 
degradation, and images showed that the surface of the flat and smooth PU film formed holes, underwent folding and experienced cracking and irregular fissuring alongside the appearance of an extensive network of fungal hypha (Fig. 5). Hypha covered the surface of the PUPB patch, and pores in the surface of the PUPB patch were clearly visible (Fig. 6).

\section{Enzyme activity by Fusarium solani H14}

Our findings revealed that the isolate Fusarium solani H14 could produce esterase and lipase, and RA is 0.46 and 0.21 , respectively (Figs 7,8 ). However, in the protease production experiment, no formation of transparent haloes around the cultures could be found.
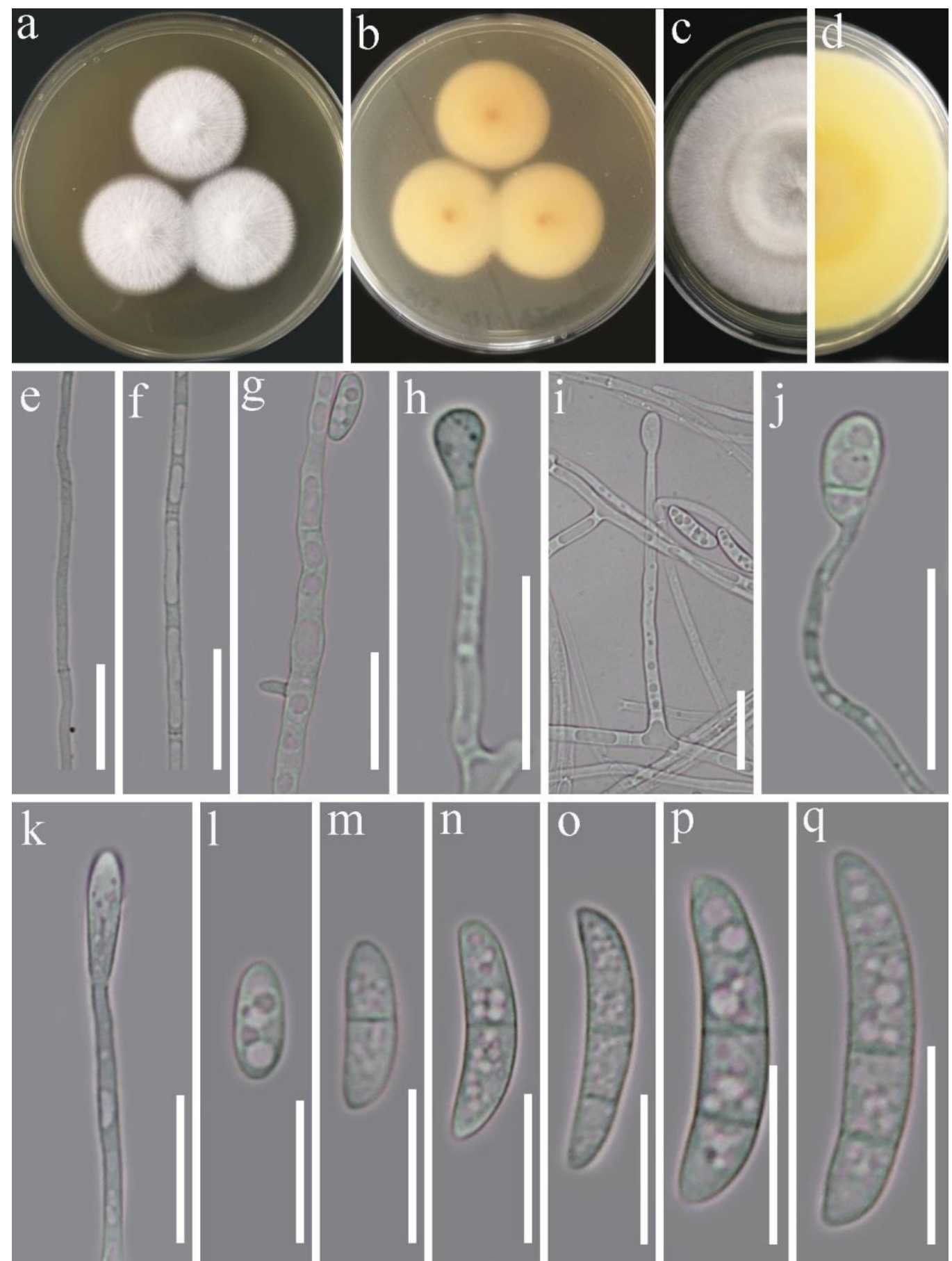

Fig. 1 - Fusarium solani (KUMCC 20-0230), a-d Sporulated culture. e-g Mycelium. $\mathrm{h}-\mathrm{k}$ Conidiogenous cell and conidia. $\mathrm{l}-\mathrm{q}$ Conidia. Scale bars: $\mathrm{e}-\mathrm{k}=20 \mu \mathrm{m}, \mathrm{l}-\mathrm{q}=15 \mu \mathrm{m}$. 


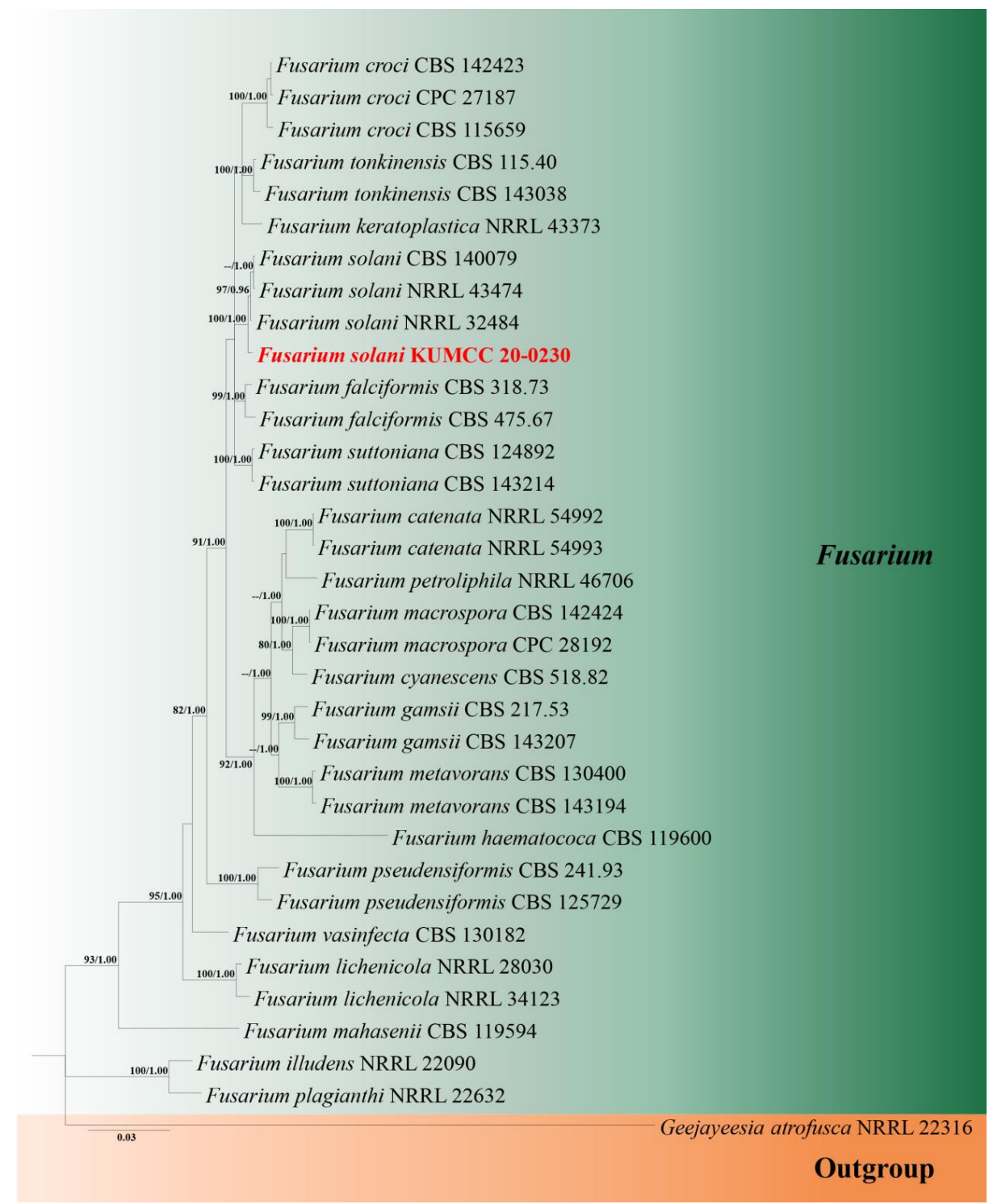

Fig. 2 - Phylogram generated from Bayesian Inference analysis based on combined LSU, ITS, tef1$\alpha$ and $r p b 2$ dataset. Bootstrap support values for maximum likelihood (ML) equal to or higher than $80 \%$ and Bayesian posterior probabilities (BYPP) equal to or greater than 0.95 are indicated above the nodes. The new isolate from this study is indicated in red bold. The tree is rooted with Geejayeesia atrofusca (NRRL 22316).

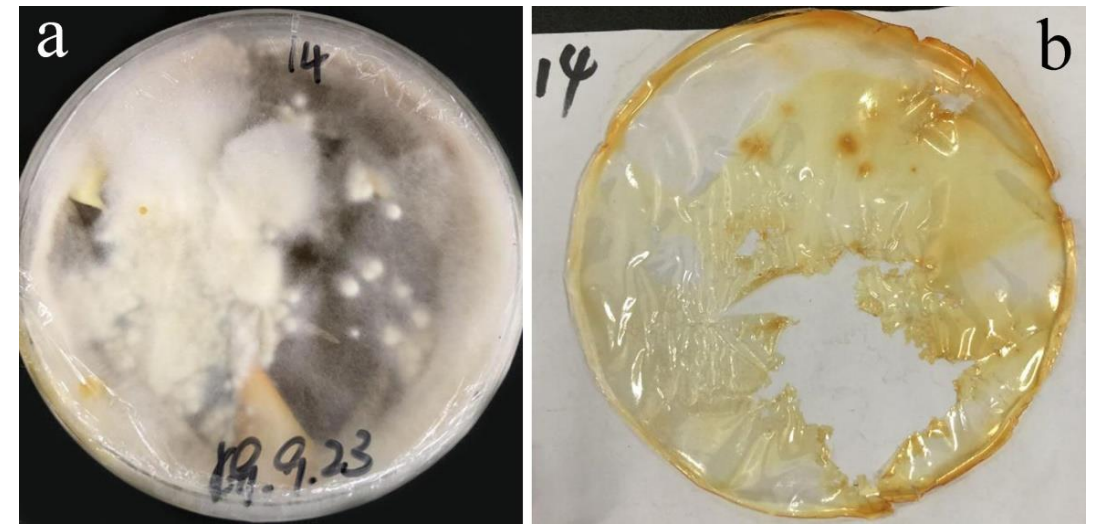

Fig. 3 - Photographs of the PU film on medium with fungal growth before and after washing. a Mycelia growth on the PU surface film 90 days after incubation. b PU film degraded by Fusarium solani $\mathrm{H} 14$. 


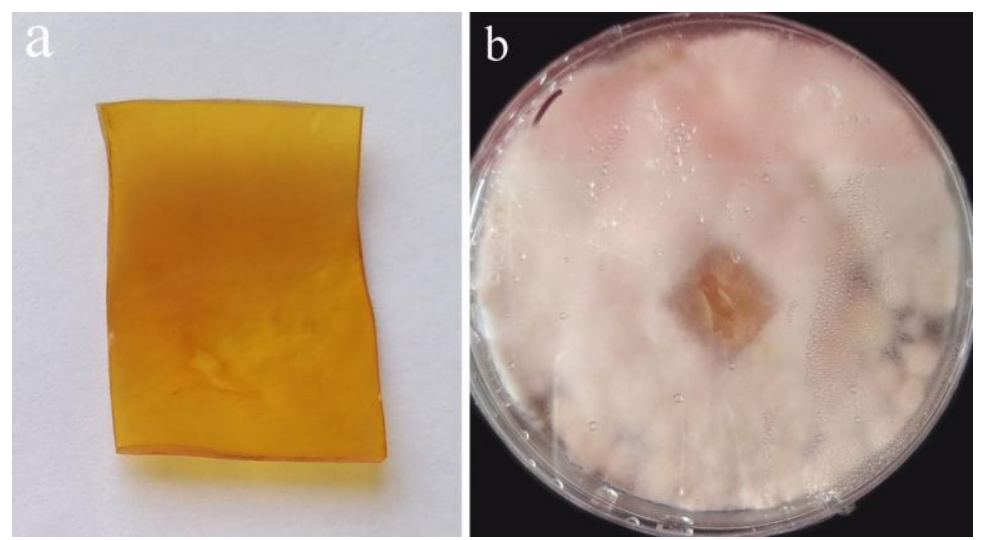

Fig. 4 - Photographs after degradation of the PUPB patch by Fusarium solani H14. a PUPBsterilized patch. b Mycelia growth on the PUPB-sterilized patch 90 days after incubation.
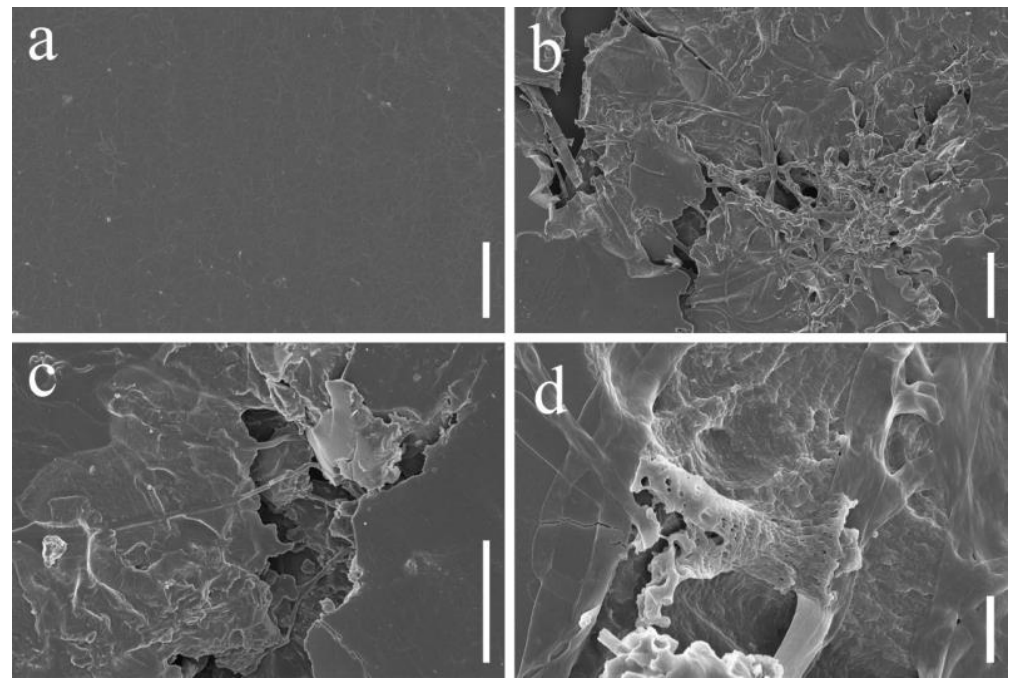

Fig. 5 - Scanning electron microscopy micrographs of PU film ultrastructure after Fusarium solani H14 growth. a Control. b-d Fusarium solani H14 with PU film 90 days after the biodegradation experiment. Scale bars: $\mathrm{a}=20 \mu \mathrm{m}, \mathrm{b}, \mathrm{c}=40 \mu \mathrm{m}, \mathrm{d}=4 \mu \mathrm{m}$.
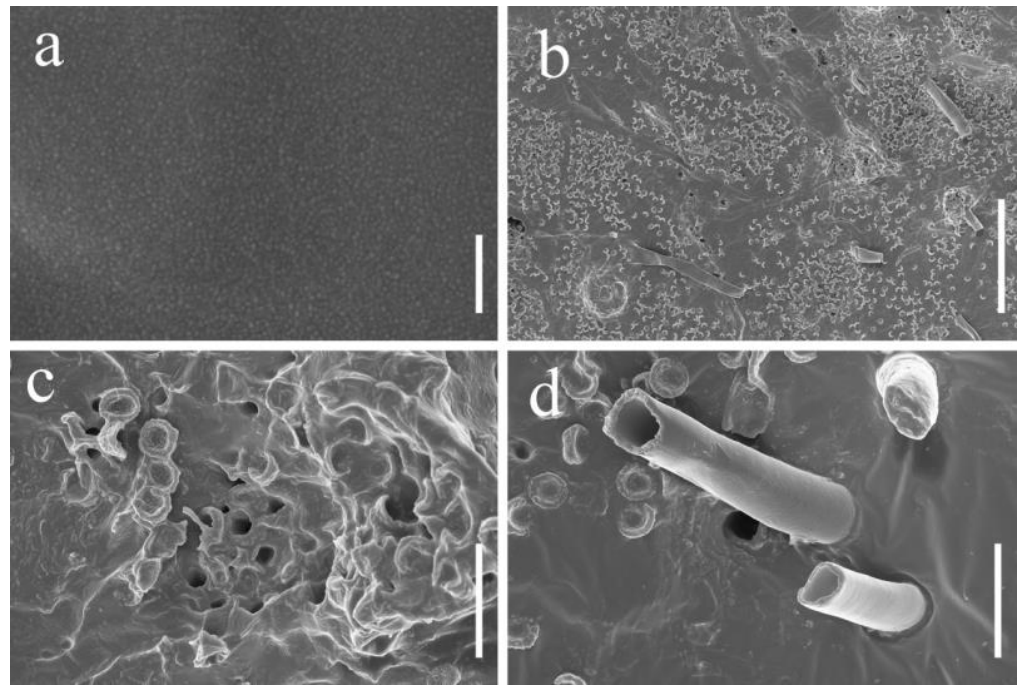

Fig. 6 - Scanning electron microscopy micrographs of the PUPB patch ultrastructure after Fusarium solani $\mathrm{H} 14$ growth. a Control. b-d Fusarium solani $\mathrm{H} 14$ with the PUPB patch 90 days after the biodegradation experiment. Scale bars: $a=100 \mathrm{~nm}, b=100 \mu \mathrm{m}, \mathrm{c}, \mathrm{d}=10 \mu \mathrm{m}$. 


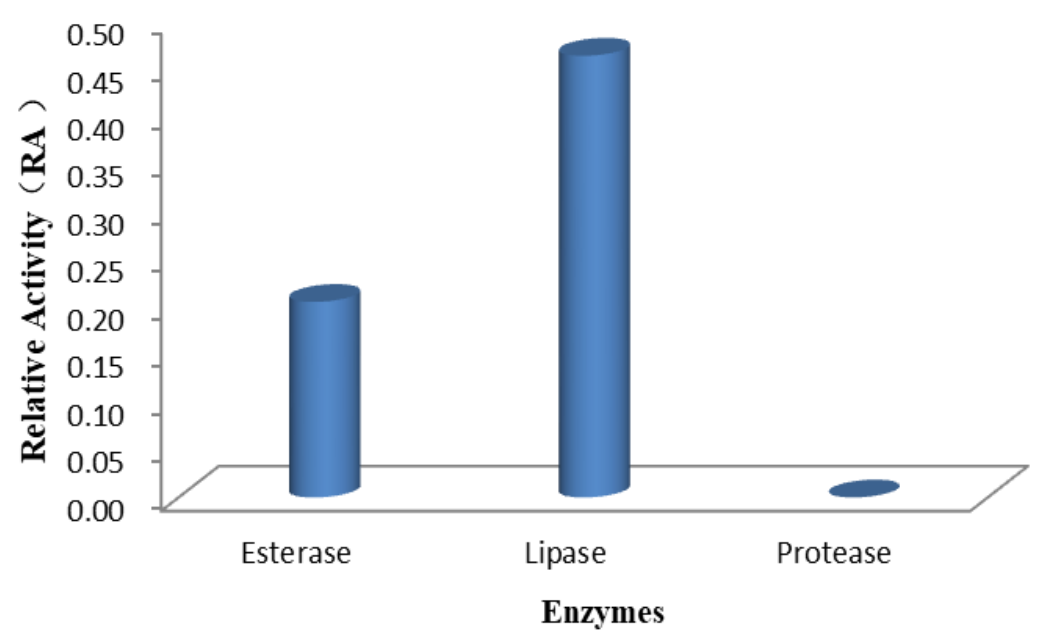

Fig. 7 - Relative enzyme activity (RA) displayed for production of enzymes by Fusarium solani H14.
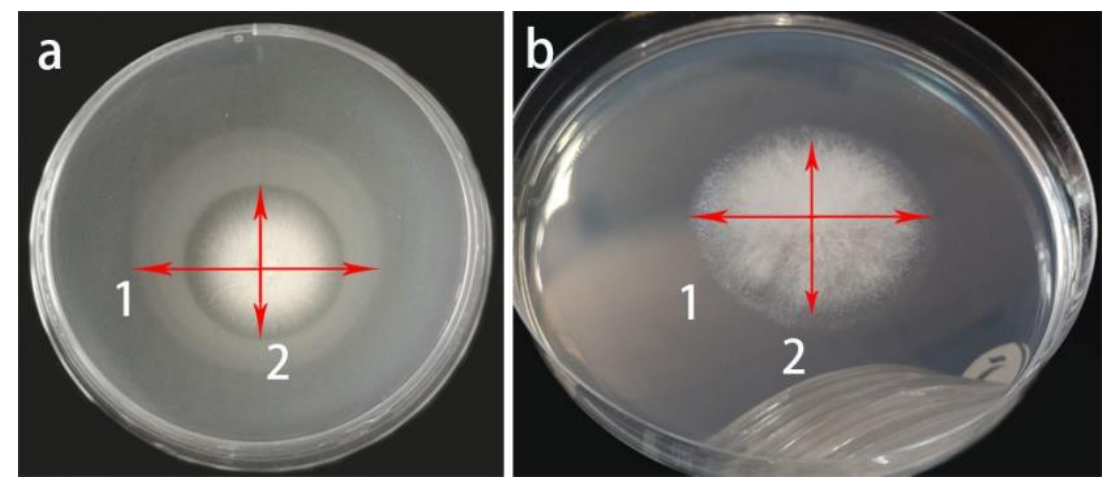

Fig. 8 - Enzyme activity by Fusarium solani H14 on medium plates. a Lipase production. b Esterase production, arrows 1 and 2 refer to colony diameter and opaque haloes diameter, respectively.

\section{Discussion}

Biodegradation as an ecologically friendly means of mitigating the accumulation of polymer types and reducing environmental pollution has attracted increasing attention in recent years. The number of polymer-degrading microorganisms isolated from different types of soils has also increased, including actinomycetes, fungi and bacteria (Zheng et al. 2005, Bhardwaj et al. 2013, Kale et al. 2015, Nakei et al. 2015, Brunner et al. 2018, Magnin et al. 2019). Fungal biodegradation of polymers remains a relatively unexplored field of study compared with bacteria and their associated enzymes (Loredo-Treviño et al. 2011). PU is susceptible to microbial attacks in acidic and neutral soils, and predominant degrading microbes are fungi under a wide range of soil (Barratt 2003, Cosgrove et al. 2007). PU degradation involves the degradation of polyester bonds and polyether bonds (Nakajima-Kambe et al. 1999). PU biodegradation results from hydrolysis of ester bonds, as the hydrolysable ester bonds are more biodegradable than polyether ones (Howard et al. 1999, Magnin et al. 2019). Studies have shown that the degradation of solid PU may be affected by the adsorption of external enzymes from clay. Therefore, in order to screen out fungi with PU- and PUPB-degrading potential, we directly isolated soil fungi to determine their degradative ability (Ibrahim et al. 2011).

In this study, Fusarium solani $\mathrm{H} 14$ was screened from soil contaminated with explosive rocket propellant material. It was found to be capable of degrading standard PU film. Results from 
the degradative testing test method indicated a $25.8 \%$ mass loss for PU by $F$. solani after 90 days, and there was a notable change on the surface of the PU film. SEM micrographs revealed that standard PU films experienced folding, cracking, and erosion along with irregular fissuring. This result is in line with previous studies (Crabbe et al. 1994, Ibrahim et al. 2011, Zafar et al. 2013). Ibrahim et al. (2011) reported $F$. solani caused significant mass loss in the PS-PUR blocks in the shaken cultures and petri dish test method, respectively, and Zafar et al. (2013) also reported $F$. solani caused significant physical deterioration. In contrast, mass loss for PUPB was relatively low (approximately 1.3\%) after 90 days of incubation with $F$. solani $\mathrm{H} 14$; however, extensive mycelia colonization and numerous holes were found on the surface of PUPB under SEM examination suggesting that PUPB degradation might be a slower process.

Effective degradation of polymer by microorganisms is directly related to polymer structure (such as molecular orientation, crystallinity, cross-linking and chemical groups present in the molecular chains) (Howard 2002) and microbial enzymes (such as ureases, proteases and esterase) (Mathur \& Prasad 2012). Other studies have reported polymer degradation involving the binding of microbial cells to polymer with subsequent floc formation, followed by degradation of the substrate; more microbial cells coated with PU has led to greater PU degradation (Howard et al. 1999, Howard 2012, El-Morsy et al. 2017, Iram et al. 2019). Furthermore, additives, antioxidants and stabilizers used in the manufacturing of polymer decelerate the rate of degradation and could also be toxic to microorganisms (Arutchelvi et al. 2008, Kale et al. 2015).

Various enzymes play essential roles in the biodegradation of polymers; these enzymes include laccase, cutinase, hydrolase, esterase, protease and urease (Barratt 2003, Loredo-Treviño et al. 2011, Bhardwaj et al. 2013). Fungi feature higher levels of enzyme biodegradation activity compared to bacteria, and enzymes are specific in their actions on substrates (Bhardwaj et al. 2013, Banerjee et al. 2014). Factors affecting the production of enzymes include PH, medium composition and temperature (Vermelho et al. 1996). Enzymes involved in polymer degradation are extracellular and membrane bound (Mathur \& Prasad 2012). In the process of degradation, extracellular enzymes function as key players and are actively involved in the biodegradation of polymers by cleaving ester bonds to degrade the PU substrate (Ibrahim et al. 2011, Raaman et al. 2012, Ma \& Wong 2013, El-Morsy et al. 2017). The biodegradation of PU begins with surface erosion initiated by microbial enzymes. The chemical process that occurs during biodegradation is usually divided into the assimilatory process and dissimilatory processes (Tan \& Ohwada 2019). In the present study, we carried out experiments on enzymes produced by $F$. solani $\mathrm{H} 14$, selected esterase, protease and lipase for the enzyme production experiment and found $F$. solani $\mathrm{H} 14$ had a high ability to produce lipase and esterase and no ability to produce protease. Lipase and esterase could play an important role in the ability of $F$. solani $\mathrm{H} 14$ to degrade PU films; however, whether the holes formed on the PUPB surface are related to lipase and esterase or other enzymes needs further study.

It is also necessary to optimize treatment conditions to improve the biodegradation capacity of $F$. solani $\mathrm{H} 14$ on PUPB by extending the degradation time, improving characteristics of the medium ( $\mathrm{PH}$, composition of medium, temperature) as well as analyzing the structure of the propellant materials and enzyme production factors. These must be carried out in order to increase hyphae colonization on PUPB (Ali et al. 2014). Our test provides a pathway for further PUPBrelated degradation experiments. Future experiments aimed at enhancing the ability of $F$. solani H14 to degrade PUBP could include a series of hybridization trials, hybridizing strain H14 and screening resultant strains for increased rates of PUBP biodegradation PUBP.

PU-degrading fungi are generally isolated from contaminated soils, sand, wall paint, plastic waste, dumping areas, compost and plastic debris floating near lakeshores (Loredo-Treviño et al. 2011, Zafar et al. 2013). However, we report on the first $F$. solani isolation from soils contaminated with explosive rocket propellant materials in China. We also are the first to report $F$. solani degradation of a propellant material prepared from an elastomer-based PUPB. Further in-depth research on the mechanisms behind PUPB biodegradation is required to solve the issue of degrading rocket propellant materials. 


\section{Conclusion}

In this study, Fusarium solani H14 was isolated from soil samples (contaminated with explosive materials) and illustrated with morphological evidence and phylogenetic analyses. The results of PU- and PUPB-degrading ability of this species can be summarized as follows: mass loss analyses revealed reductions in mass of standard PU film and PUPB patches; and scanning electron microscopy images showed that the surface of the standard PU film and PUPB patches formed holes, underwent folding and experienced damage and irregular fissuring from the erosion of fungal hypha. Two possible degradation enzymes, lipase and esterase, were produced by $F$. solani H14. The above findings confirm the degradation effect of $F$. solani $\mathrm{H} 14$ on standard PU film and PUPB patches. This is a preliminary study that provides a potential roadmap for solving problems associated with environmental pollution, particularly related to disposing rocket propellant waste materials via microbial degradation in the future.

\section{Acknowledgements}

This work was financed by Open Research Fund Program of Science and Technology on Aerospace Chemical Power Laboratory (STACPL320181B04). We also would like to thank the support from the National Natural Science Foundation of China (NSFC21975066, NSFC21875061).

\section{References}

Ali MI, Ahmed S, Robson G, Javed I et al. 2014 - Isolation and molecular characterization of polyvinyl chloride (PVC) plastic degrading fungal isolates. Journal of Basic Microbiology 54, $18-27$.

Álvarez-Barragán J, Domínguez-Malfavón L, Vargas-Suárez M, GonzálezHernández R. 2016 Biodegradative activities of selected environmental fungi on a polyester polyurethane varnish and polyether polyurethane foams. Applied and Environmental Microbiology 82, 5225-5235.

Arutchelvi J, Sudhakar M, Arkatkar A, Doble M et al. 2008 - Biodegradation of polyethylene and polypropylene. Indian J Biotechnol 7, 9-22.

Banerjee A, Chatterjee K, Madras G. 2014 - Enzymatic degradation of polymers: a brief review. Materials Science and Technology 30, 567-573.

Barratt SR, Ennos AR, Greenhalgh M, Robson GD, Handley PS. 2003 - Fungi are the predominant micro-organisms responsible for degradation of soil-buried polyester polyurethane over a range of soil water holding capacities. Journal of Applied Microbiology 95, 78-85.

Bhardwaj H, Gupta R, Tiwari A. 2013 - Communities of microbial enzymes associated with biodegradation of plastics. Journal of polymers and the environment 21, 575-579.

Bradner JR, Gillings M, Nevalainen KMH. 1999 - Qualitative assessment of hydrolytic activities in Antarctic microfungi grown at different temperatures on solid media. World Journal of Microbiology and Biotechnology 15, 131-132.

Brunner I, Fischer M, Rüthi J, Stierli B, Frey B. 2018 - Ability of fungi isolated from plastic debris floating in the shoreline of a lake to degrade plastics. PLOS ONE 13, e0202047.

Bunyan P, Cunliffe AV, Davist A, Kirby FA. 1993 - The degradation and stabilisation of solid rocket propellants. Polymer Degradation and Stability 40, 239-250.

Castro GR, Stettler AO, Ferrero MA, Sifieriz F. 1992 - Selection of an extracellular esterase producing microorganism. Journal of Industrial Microbiology 10, 165-168.

Cosgrove L, McGeechan PL, Robson GD, Handley PS. 2007 - Fungal communities associated with degradation of polyester polyurethane in soil. Applied and Environ Microbiology 73, 5817-5824.

Crabbe JR, Campbell JR, Thompson L, Walz SL, Schultz WW. 1994 - Biodegradation of a colloidal ester-based polyurethane by soil fungi. International Biodeterioration and Biodegradation 33, 103-113. 
Davenas A. 2003 - Development of Modern Solid Propellants. Journal of propulsion and power 19, $1108-1128$.

El-Morsy EM, Hassan HM, Ahmed E. 2017 - Biodegradative activities of fungal isolates from plastic contaminated soils. Mycosphere 8, 1071-1087.

Gautam R, Bassi AS, Yanful EK. 2007 - A review of biodegradation of synthetic plastic and foams. Applied Biochemistry and Biotechnology 141, 85-108.

Hall TA. 1999 - BioEdit: a user-friendly biological sequence alignment editor and analysis program for Windows 95/98/NT. Nucleic Acids Symposium Series 41, 95-98.

Haska SB, Bayramli E, Pekel F, Ozkar S. 1997 - Mechanical properties of HTPB-IPDI-based elastomers. Journal of Applied Polymer Science 64, 2347-2354.

Howard GT. 2002 - Biodegradation of polyurethane: a review. International Biodeterioration and Biodegradation 49, 245-252.

Howard GT. 2012 - Polyurethane biodegradation. In: Singh S.N. (ed) Microbial degradation of xenobiotics. Springer, Berlin, Heidelberg, pp 371-394.

Howard GT, Ruiz C, Hilliard NP. 1999 - Growth of Pseudomonas chlororaphis on a polyesterpolyurethane and the purification and characterization of a polyurethanase-esterase enzyme. International Biodeterioration and Biodegradation 43, 7-12.

Ibrahim IN, Maraqa A, Hameed KM, Saadoun IM, Maswadeh HM. 2011 - Assessment of potential plastic-degrading fungi in Jordanian habitats. Turkish Journal of Biology 35, 551-557.

Iram D, Riaz RA, Iqbal RK. 2019 - Usage of Potential Micro-organisms for Degradation of Plastics. Open Journal of Environmental Biology 4, 007-0015.

Kale SK, Deshmukh AG, Dudhare M, Patil V. 2015 - Microbial degradation of plastic: a review. Journal of Biochemical Technology 6, 952-961.

Katoh K, Rozewicki J, Yamada KD. 2019 - MAFFT online service: multiple sequence alignment, interactive sequence choice and visualization. Briefings in bioinformatics 20, 1160-1166.

Khan S, Nadir S, Shah ZU, Shah AA et al. 2017 - Biodegradation of Polyester Polyurethane by Aspergillus Tubingensis. Environmental Pollution 225, 469-480.

Khan S, Nadir S, Dong Y, Schaefer DA et al. 2020 - Biodegradation of polyester polyurethane by Aspergillus flavus G10. (BioRxiv).

Krasowska K, Janik H, Gradys A, Rutkowska M. 2012 - Degradation of polyurethanes in compost under natural conditions. Journal of Applied Polymer Science 125, 4252-4260.

Libardi J, Ravagnani SP, Morais AMF, Cardoso AR. 2010 - Diffusion of Plasticizer in a Solid Propellant Based on Hydroxyl-Terminated Polybutadiene. Polímeros 20, 241-245.

Liu YJ, Whelen S, Hall BD. 1999 - Phylogenetic relationships among ascomycetes: evidence from an RNA polymerase II subunit. Molecular Biology and Evolution 16, 1799-1808.

Loredo-Treviño A, García G, Velasco-Téllez A, Rodríguez-Herrera R, Aguilar CN. 2011 Polyurethane foam as substrate for fungal strains. Advances in Bioscience and Biotechnology 2, 52-58.

Ma A, Wong Q. 2013 - Dentification of esterase in Fusarium solani during degradation of polyester polyurethane. Canadian young scientist 2, 24-29.

Magnin A, Hoornaert L, Pollet E, Laurichesse S, Phalip V. 2019 - Isolation and characterization of different promising fungi for biological waste management of polyurethanes. Microbial Biotechnology 12, 544-555.

Mahajan N, Gupta P. 2015 - New insights into the microbial degradation of polyurethanes. RSC Advances 5, 41839-41854.

Mathur G, Prasad R. 2012 - Degradation of polyurethane by Fusarium solani (ITCC 6051) isolated from soil. Applied Biochemistry and Biotechnology 167, 1595-1602.

Miller MA, Pfeiffer W, Schwartz T. 2010 - Creating the CIPRES Science Gateway for inference of large phylogenetic trees. In Proceedings of the Gateway Computing Environments Workshop (GCE), New Orleans, LA. Pp. 1-8. 
Nakajima-Kambe T, Shigeno-Akutsu Y, Nomura N, Onuma F, Nakahara T. 1999 - Microbial degradation of polyurethane, polyester polyurethanes and polyether polyurethanes. Appl Microbiol Biotechnol 51, 134-40.

Nakei MD. 2015 - Isolation and Identification of Plastic-degrading Microorganisms from soils of morogoro, Tanzania.

O’Donnell K, Kistler HC, Cigelnik E, Ploetz RC. 1998 - Multiple evolutionary origins of the fungus causing Panama disease of banana: concordant evidence from nuclear and mitochondrial gene genealogies. Proc. Natl. Acad. Sci. USA. 95, 2044-2049.

Pathak VM, Navneet. 2017 - Review on the current status of polymer degradation: a microbial approach. Bioresour and Bioprocess 4, 15.

Pichtel J. 2012 - Distribution and Fate of Military Explosives and Propellants in Soil: A Review. Applied and Environmental Soil Science. SP: 617236, 33 pages.

Raaman N, Rajitha N, Jayshree A, Jegadeesh R. 2012 - Biodegradation of plastic by Aspergillus spp. isolated from polythene polluted sites around Chennai. Journal of Academia and Industrial Research 1, 2278-5213.

Rambaut A. 2012 - FigTree version 1.4.0. Available.

Reeb V, Lutzoni F, Roux C. 2004 - Contribution of RPB2 to multilocus phylogenetic studies of the euascomycetes (Pezizomycotina, Fungi) with special emphasis on the lichen-forming Acarosporaceae and evolution of polyspory. Molecular Phylogenetics and Evolution 32, 1036-1060.

Sangale MK, Shahnawaz M, Ade AB. 2019 - Potential of fungi isolated from the dumping sites mangrove rhizosphere soil to degrade polythene. Scientific Reports 9, 5390.

Sarkhel R, Sengupta S, Das P, Bhowal A. 2019 - Comparative biodegradation study of polymer from plastic bottle waste using novel isolated bacteria and fungi from marine source. Journal of Polymer Research 27, 16.

Sierra G. 1956 - A simple method for the detection of lipolytic activity of microorganisms and some observations on the influence of the contact between cells and fatty substrates. Antonie van Leeuwenhoek 23, 15-22.

Stamatakis A. 2014 - RAxML Version 8: A tool for Phylogenetic Analysis and Post-Analysis of Large Phylogenies. Bioinformatics 30, 1312-1313.

Tan JD, Ohwada T. 2019 - Isolation and identification of microorganisms for polyurethane degradation. Annals of Tropical Research 41, 57-66.

Thompson JD, Gibson TJ, Plewniak F, Jeanmougin F, Higgins DG. 1997 - The ClustalX windows interface: flexible strategies for multiple sequence alignment aided by quality analysis tools. Nucleic Acids Research 24, 4876-4882.

Tokiwa Y, Calabia BP. 2009 - Biodegradability of plastics. International Journal of Molecular Sciences 10, 3722-3742.

Vermelho BA, Meirelles MN, Lopes A, Petinate SD et al. 1996 - Detection of extracellular protease from Microorganisms on agar plates. Memórias do Instituto Oswaldo Cruz 91, 755760 .

Vilgalys R, Hester M. 1990 - Rapid genetic identification and mapping of enzymatically amplified ribosomal DNA from several Cryptococcus species. Journal of Bacteriology 172, 4238-4246.

Waksman SA. 1922 - A method for counting the number of fungi in the soil. Journal of Bacteriology 7, 339-341.

Wang MM, Chen Q, Diao YZ, Duan WJ, Cai L. 2019 - Fusarium incarnatum-equiseti complex from China. Persoonia 43, 70-89.

White TJ, Bruns T, Lee S, Taylor JW. 1990 - Amplification and direct sequencing of fungal ribosomal RNA genes for phylogenetics. PCR protocols: A Guide to Methods and Applications. Academic Press, San Diego, pp. 315-322.

Zafar U, Houlden A, Robson GD. 2013 - Fungal communities associated with the biodegradation of polyester polyurethane buried under compost at different temperatures. Applied and Environmental Microbiology 79, 7313-7324. 
Zheng Y, Yanful EK, Bassi AS. 2005 - A Review of Plastic Waste Biodegradation, Critical Reviews in Biotechnology 25, 243-250. 